\title{
Prenatal nicotine increases pulmonary $\alpha 7$ nicotinic receptor expression and alters fetal lung development in monkeys
}

\author{
Harmanjatinder S. Sekhon, ${ }^{1}$ Yibing Jia, ${ }^{1}$ Renee Raab, ${ }^{1}$ Alexander Kuryatov, ${ }^{2}$ \\ James F. Pankow, ${ }^{3}$ Jeffrey A. Whitsett, ${ }^{4}$ Jon Lindstrom, ${ }^{2}$ and Eliot R. Spindel ${ }^{1}$ \\ ${ }^{1}$ Division of Neuroscience, Oregon Regional Primate Research Center, Beaverton, Oregon 97006, USA \\ ${ }^{2}$ Department of Neuroscience, University of Pennsylvania, Philadelphia, Pennsylvania 19104, USA \\ ${ }^{3}$ Department of Environmental Sciences and Engineering, Oregon Graduate Institute of Science and Technology, \\ Beaverton, Oregon 97006, USA \\ ${ }^{4}$ Divisions of Neonatology and Pulmonary Biology, Children's Hospital, Cincinnati, Ohio 45229, USA \\ Address correspondence to: Eliot Spindel, Division of Neuroscience, Oregon Regional Primate Research Center, \\ 505 NW 185th Avenue, Beaverton, Oregon 97006, USA. Phone: (503) 690-5512; Fax: (503) 690-5384; \\ E-mail: Spindele@ohsu.edu \\ Received for publication September 15, 1998, and accepted in revised form January 15, 1999.
}

\begin{abstract}
It is well established that maternal smoking during pregnancy is a leading preventable cause of low birth weight and prematurity. Less appreciated is that maternal smoking during pregnancy is also associated with alterations in pulmonary function at birth and greater incidence of respiratory illnesses after birth. To determine if this is the direct result of nicotine interacting with nicotinic cholinergic receptors (nAChRs) during lung development, rhesus monkeys were treated with $1 \mathrm{mg} / \mathrm{kg} /$ day of nicotine from days 26 to 134 of pregnancy. Nicotine administration caused lung hypoplasia and reduced surface complexity of developing alveoli. Immunohistochemistry and in situ $\alpha$-bungarotoxin $(\alpha \mathrm{BGT})$ binding showed that $\alpha 7 \mathrm{nAChRs}$ are present in the developing lung in airway epithelial cells, cells surrounding large airways and blood vessels, alveolar type II cells, free alveolar macrophages, and pulmonary neuroendocrine cells (PNEC). As detected both by immunohistochemistry and by $\alpha \mathrm{BGT}$ binding, nicotine administration markedly increased $\alpha 7$ receptor subunit expression and binding in the fetal lung. Correlating with areas of increased $\alpha 7$ expression, collagen expression surrounding large airways and vessels was significantly increased. Nicotine also significantly increased numbers of type II cells and neuroendocrine cells in neuroepithelial bodies. These findings demonstrate that nicotine can alter fetal monkey lung development by crossing the placenta to interact directly with nicotinic receptors on nonneuronal cells in the developing lung, and that similar effects likely occur in human infants whose mothers smoke during pregnancy.
\end{abstract}

J. Clin. Invest. 103:637-647 (1999)

\section{Introduction}

It is well known that smoking during pregnancy is the largest preventable cause of low birth weight, premature delivery, neonatal morbidity, and mortality $(1,2)$. Perhaps less well appreciated is the recent, strong evidence that smoking during pregnancy directly and adversely effects lung development, as manifested by altered pulmonary function and increased respiratory illness in children born of smoking mothers (3-6). Stoddard and Gray (7) recently estimated that annual costs of increased respiratory illness associated with maternal smoking is in excess of 660 million dollars per year. How smoking produces these effects is not fully understood. While the cause of pulmonary damage caused by maternal smoking is likely to be multifactorial, evidence presented in this paper indicates that much of the effect of maternal smoking on the lung may be mediated by the interaction of nicotine with nicotinic receptors expressed in the developing lung.

Multiple studies have shown increased lower respiratory illness in infants born of mothers who smoke $(3,4)$. Taylor and Wadsworth (3) studied 12,743 children and found significantly increased bronchitis and hospital admissions for lower respiratory illness in children from smoking moth- ers. Significantly increased hospital admissions were not seen for children whose mothers smoked only after pregnancy, arguing for a prenatal effect. Tager et al. (4) similarly found increased lower respiratory illness with prenatal smoke exposure, but not with postnatal exposure. Correlating the increased respiratory illness with altered pulmonary function, Hanrahan et al. (5) examined pulmonary function of infants shortly after birth ( $\sim 4.2$ weeks) as a function of smoking during pregnancy (determined both by questionnaire and by urinary cotinine) and found decreased respiratory flow rates. In a follow-up study, Tager et al. (4) showed that the decreased ventilation at functional residual capacity (VFRC) seen with prenatal smoke exposure correlated directly with increased lower respiratory illnesses. Cunningham et al. (6) performed pulmonary function tests on 8,800 nonsmoking school children 8-12 years old and similarly found reduced forced expiratory flow in children whose mothers smoked during pregnancy. Again the correlation was with prenatal, not postnatal, maternal smoking. This confirmed the earlier studies and suggested the deficit continued at least to adolescence.

Animal studies on the effects of smoking or nicotine on lung development have been quite limited, and there have been no studies of potential molecular mechanisms. 
Table 1

Morphometric alterations in 134-day fetal lung after maternal nicotine treatment

\begin{tabular}{lccc}
\hline Variable & Control $(n=3)$ & Nicotine $(n=3)$ & $P$-value \\
Total lung weight $(\mathrm{g})$ & $9.03 \pm 0.26$ & $7.86 \pm 0.83$ & $\mathrm{NS}$ \\
Total lung volume & $13.07 \pm 0.28$ & $11.45 \pm 0.61$ & $\mathrm{NS}$ \\
Mean linear intercept $(\mu \mathrm{m})$ & $79.15 \pm 1.52$ & $87.44 \pm 0.8$ & 0.009 \\
Internal surface area $\left(\mathrm{m}^{2}\right)$ & $0.661 \pm 0.020$ & $0.523 \pm 0.025$ & 0.014 \\
Valv & $40.76 \pm 0.73$ & $47.65 \pm 1.5$ & 0.014 \\
Vd & $23.26 \pm 2.82$ & $20.48 \pm 0.77$ & $\mathrm{NS}$ \\
Vwall & $27.99 \pm 1.69$ & $24.63 \pm 1.40$ & $\mathrm{NS}$ \\
Vbrair & $3.89 \pm 0.97$ & $2.84 \pm 0.68$ & $\mathrm{NS}$ \\
Vnon-par & $4.11 \pm 0.46$ & $4.4 \pm 0.28$ & $\mathrm{NS}$
\end{tabular}

Values are mean \pm SE. NS, not significant; Valv, volume density of alveolar air; Vbrair, volume density of bronchial air; $V d$, volume density of alveolar duct; $V$ non-par, volume density of nonparenchyma; Vwall, volume density of alveolar wall.

Collins et al. (8) showed that in rats, cigarette smoke exposure during days 5-20 of gestation caused reduction in lung volume, number of saccules and septal crests, and elastin fibers in fetal lungs. In addition, Maritz et al. $(9,10)$ showed that nicotine exposure during pregnancy and lactation produced emphysema-like changes, reduction in elastic tissue, and increased number of lamellar bodies in the lungs of the rat pups. Although it appears evident that maternal cigarette smoke or nicotine exposure produces adverse effects in the offspring lungs, mechanisms responsible for inducing these changes are yet to be determined. Compared with humans and monkeys, rodent lungs are relatively immature at birth (11). This makes monkeys valuable when studying the effects of chronic, low-dose nicotine on lung development as a model of the effects of maternal smoking on lung development.

The nicotinic cholinergic receptors belong to the family of ligand-gated ion channels that also include the glycine, $\mathrm{GABA}_{\mathrm{A}}$, and $5 \mathrm{HT} 3$ receptors (12). The receptor is composed of five homologous subunits arranged around a central ion channel, such that binding of acetylcholine allows ion flow through the channel (generally sodium or calcium). Thirteen genes that code for nicotinic subunits have been identified to date: four $\beta$ subunits and nine $\alpha$ subunits. Nicotinic receptors can be heteromers composed of both $\alpha$ and $\beta$ subunits, or homomers composed only of one type of $\alpha$ receptor. In the brain, the most abundant heteromeric form is $(\alpha 4)_{2}(\beta 2)_{3}$; the most abundant homomeric form is $(\alpha 7)_{5}$. Agonist and antagonist sensitivity is primarily conveyed by which $\alpha$ subunit(s) is present, though the $\beta$ subunits can modify that sensitivity. Chronic nicotine exposure has been shown to upregulate nicotinic receptor expression in vitro $(12,13)$ in adult humans and rodents $(14,15)$, and consistent with this, exposure of pregnant rats to nicotine changes nicotinic receptor expression in brains of the offspring $(16,17)$.

The expression of nicotinic receptors in the adult lung has only recently been addressed. Zia et al. (18) found that $\alpha 3, \alpha 5$, and $\alpha 7$ subunits could be detected in human and mouse bronchial epithelial cells; $\alpha 4$ subunits were present in alveolar epithelial cells, and $\alpha 7$ subunits in submucosal glands. Maus et al. (19) similarly detected $\alpha 3$ and $\alpha 5$ subunits in bronchial epithelial cells and demonstrated by patch clamping that they formed functional channels. $\alpha 7$ receptors have also been reported in SCLC and SCLC cell lines, and the growth of these cell lines can be inhibited by $\alpha$-bungarotoxin $(\alpha B G T)$, a specific antagonist of $\alpha 7$ receptors (20). There have been, however, no studies on the expression of nicotinic receptors in developing lung nor on the effects of nicotine on those receptors in developing lung.

In this paper, we report that abundant nicotinic receptors are expressed in developing lung and that nicotine administered to pregnant monkeys crosses the placenta to interact with those receptors. This interaction leads to altered expression of nicotinic receptors in pulmonary cells, alterations in gene expression, and alterations in lung development.

\section{Methods}

Experimental design. Six pregnant rhesus female monkeys were randomly assigned to a control or nicotine treatment group. Timed pregnancy was determined by consistently high levels of blood estrogen and progesterone on days 19, 21, and 23 after mating (21). On the 26th day of gestation, pregnancy was confirmed by ultrasound and Alzet mini osmotic 2ML4 pumps (ALZA Corp., Palo Alto, California, USA) containing nicotine tartrate (Sigma Chemical Co., St. Louis, Missouri, USA) in normal saline to deliver $1 \mathrm{mg} / \mathrm{kg}$ body weight/day were placed subcutaneously in the midscapular region. Mothers were weighed routinely to determine untoward effects of nicotine delivery. Pumps were replaced every 4 weeks. On days 92, 106, and 120 of gestation, a sample of amniotic fluid was taken by amniocentesis for surfactant protein measurements. Animals received Cefazolin (150 mg twice a day) for three days after pump insertion and amniocentesis. Control animals did not receive minipumps, but pump insertions were timed to coincide with amniocenteses on days 92 and 120, at which time control animals also received anesthetic and antibiotic.

On day 134 of gestation, fetuses were obtained by cesarean section, and amniotic fluid and cord blood samples were obtained. Lungs were flushed with normal saline to remove residual blood volume, dissected out, blotted, and weighed. The right lung was removed after ligating the bronchus, sliced into 1 -mm-thick blocks, and fixed overnight either in cold $4 \%$ paraformaldehyde in borate buffer ( $\mathrm{pH}$ 9.5) or in Bouin's fixative. The following day, lung blocks were rinsed in $0.05 \mathrm{M}$ PBS. Paraformaldehyde-fixed tissue was transferred to $15 \%$ sucrose and then embedded in OCT compound (Sakura Finetek, Torrance, California, USA), frozen on dry ice, and stored at $-80^{\circ} \mathrm{C}$. Tissue fixed in Bouin's fixative was processed and embedded in paraffin.

\section{Table 2}

Type II cell number and function in 134-day fetal monkey lung

\begin{tabular}{lccc}
\hline Variable & Controls & Nicotine & $P$ \\
Type Il cells $/ \mathrm{mm}^{2}$ & $2286 \pm 1225$ & $3570 \pm 257$ & 0.01 \\
Type II cell labeling index & $11.4 \pm 1.1$ & $14.2 \pm 0.5$ & 0.04 \\
SP-A mRNA/Vwall & $301.9 \pm 7.8$ & $579.9 \pm 163.3$ & NS \\
SP-B mRNA/Vwall & $513.3 \pm 48.4$ & $760.1 \pm 65.5$ & 0.02 \\
SP-A in amniotic fluid $(\mu \mathrm{g} / \mathrm{ml})$ & $12.6 \pm 0.8$ & $19.4 \pm 5.3$ & NS \\
SP-B in amniotic fluid $(\mu \mathrm{g} / \mathrm{ml})$ & $9.8 \pm 2.8$ & $22.6 \pm 5.0$ & 0.04
\end{tabular}

Type II cells $/ \mathrm{mm}^{2}$ equals number of SP-A mRNA positive cells per $\mathrm{mm}^{2}$ parenchyma. SP-A and SP-B mRNA expression (OD, see Methods). Values are mean $\pm \mathrm{SE}$ $S P-A$ and $S P-B$, rhesus surfactant proteins $A$ and $B$. 


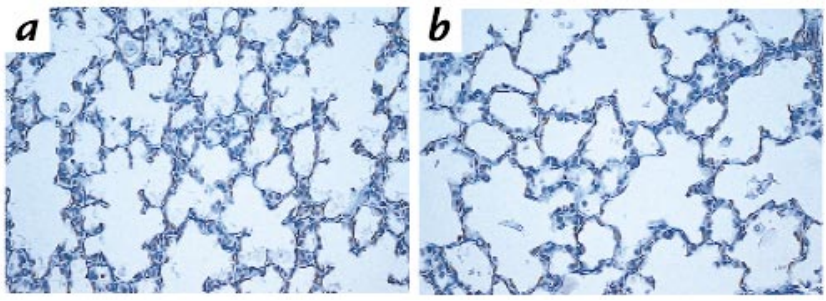

Figure 1

Effect of prenatal exposure to nicotine on lung structure. Hematoxylinstained sections from control (a) and nicotine-treated $(\boldsymbol{b})$ 134-day fetal monkey lungs. The left lung with intact trachea was fixed with $10 \%$ buffered formaldehyde at $20 \mathrm{~cm}$ constant transpulmonary water pressure for $72 \mathrm{~h}$. Midsagittal blocks were cut, embedded in paraffin, and 5 $\mu \mathrm{m}$ sections cut. $\times 400$

For morphometric analysis, the left lung with intact trachea was fixed with $4 \%$ zinc formalin (Sigma Chemical Co.) at $20 \mathrm{~cm}$ constant transpulmonary water pressure for $72 \mathrm{~h}$. Left lung volume was measured by water displacement (22) and extrapolated to obtain total lung volume using total lung weight. Nine midsagittal blocks were cut, processed, and embedded in paraffin. Sections $(5 \mu \mathrm{m})$ from each block were cut and stained with hematoxylin and eosin.

Morphometric analysis. Hematoxylin- and eosin-stained sections of left lung were used for standard morphometric analysis (23) with modifications. Sixty randomly selected nonoverlapping fields from sections obtained from nine blocks were included for the measurements. Each field obtained with a 20x objective was scanned with a digital camera (DKC-5000; Sony Corp., Tokyo, Japan) and projected onto a video monitor. A precalibrated 100 equidistant-point grid with a diagonally placed cross-hairline was placed on the image of each field. Because monkey lungs on day 134 of gestation are in late saccular and early alveolar phase of development $(24,25)$, from here on we will refer to respiratory unit structures as primitive alveoli or just alveoli. Each point that fell on alveolar air, alveolar duct, alveolar wall, bronchial air, and nonparenchyma was recorded. Every time the gas-exchange surface intercepted the diagonally placed cross-hairline it was counted as one intercept. The volume densities of alveolar air, alveolar duct, alveolar wall, bronchial air, and nonparenchyma were computed using the point-counting values. Intercept count was used to determine the mean linear intercept of airspaces. Internal surface area of the lung was calculated using mean linear intercept and lung volume. Collagen was stained by Masson's trichrome (Sigma Chemical Co.). Area of collagen staining was determined by obtaining digital images of all cartilaginous airways in three independent sections from each animal with the Sony DKC5000 imaging system. The digital images were analyzed using the MetaMorph Imaging System (Universal Imaging Corp., West Chester, Pennsylvania, USA). After setting a color threshold, collagen staining was digitized, selected, and binarized. Integrated area of the selected region was measured and expressed as square micrometer of collagen staining per micrometer of airway epithelial basement membrane.

Immunobistochemistry. Sections $(5 \mu \mathrm{m})$ from Bouin's-fixed tissue were deparaffinized and rehydrated through descending alcohol series and in PBS. Antigen was retrieved with Antigen Retrieval Citra (BioGenex Laboratories, San Ramon, California, USA) treatment, and endogenous peroxidase was quenched with $1.5 \%$ hydrogen peroxide in methanol. After blocking nonspecific antigen binding sites with $3 \%$ nonimmune serum, rat monoclonal antibodies (MABs) to nAChR subunits were applied overnight at $4^{\circ} \mathrm{C}$. Antibodies used were MAB 35 (26), MAB 210 (26), and MAB 319 (26-28). After rinsing with PBS, sections were incubated with biotinylated secondary antibody and then with peroxidase conjugated avidin solution (Vector Laboratories Inc., Burlingame, California, USA). Peroxidase was visualized with AEC (3-amino-9-ethylcarbazole) chromogen and counterstained with hematoxylin.

To assess changes in the $\alpha 7 \mathrm{nAChR}$ subunit staining after nicotine treatment, digital images of cartilaginous and membranous airways were obtained and analyzed as described above. After setting the color threshold, the region along the basement membrane was digitized, selected and binarized. Integrated area of the selected region was measured and expressed per millimeter length of basement membrane for both cartilaginous and membranous airways.

Colocalization of $\alpha 7 \mathrm{nAChR}$ subunit expression and neuroendocrine cells was determined by double immunofluorescent labeling. Antigen was retrieved as described above. Sections were incubated overnight at $4{ }^{\circ} \mathrm{C}$ with a mixture of anti-human $\alpha 7 \mathrm{nAChR}$ subunit rat and anti-human chromogranin mouse MABs (DAKO Corp., Carpinteria, California, USA). Thereafter, a mixture of Texas red-conjugated anti-rat and fluorescein-conjugated anti-mouse secondary antibodies was applied at room temperature for $1 \mathrm{~h}$. Sections were rinsed and mounted with Vectashield (Vector Laboratories Inc.). Colocalization of signals was visualized using a confocal microscope (Leica, Heidelberg, Germany).

Nicotine assay. Nicotine in day 134 amniotic fluid samples was assayed by gas chromatography-mass spectrometry (GC-MS) as described previously (29). Deuterated nicotine was added as an
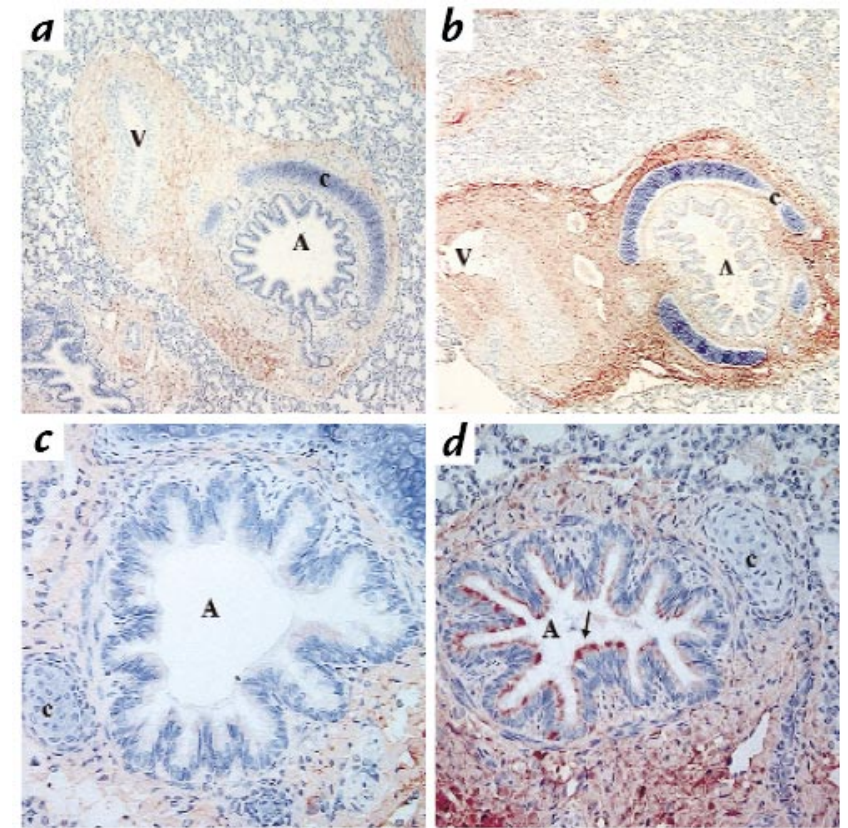

\section{Figure 2}

Immunohistochemical localization of nicotinic receptor subtypes in 134day fetal monkey lung. $\boldsymbol{a}$ and $\boldsymbol{c}$ from control fetus; $\boldsymbol{b}$ and $\boldsymbol{d}$ from nicotineexposed fetus. (a) Anti- $\alpha 7$ (MAB 319) showing brownish-red staining in fibroblast cell layer in cartilaginous airways and vessel walls. $\times 100$. (b) In nicotine-exposed fetus, greatly enhanced $\alpha 7$ staining is seen in cartilaginous airway and vessel walls. $\times 100$. No immunostaining was seen with nonimmune serum (not shown). ( $c$ and $d$ ) Higher-power view of smaller cartilaginous airways showing relatively little $\alpha 7$ in airway wall and epithelial cell lining in control lung, but intense staining in airway wall and epithelial cells (arrows) from nicotine exposed lung. $\times 400$. Procedure as described in the research plan: $\mathrm{AEC}$ was used as immunoperoxidase substrate, and hematoxylin was used as counterstain. $A$, airway lumen; $V$, blood vessel lumen; $C$, cartilage; $A E C$, 3-amino-9-ethylcarbazole; $M A B$, monoclonal antibody. 

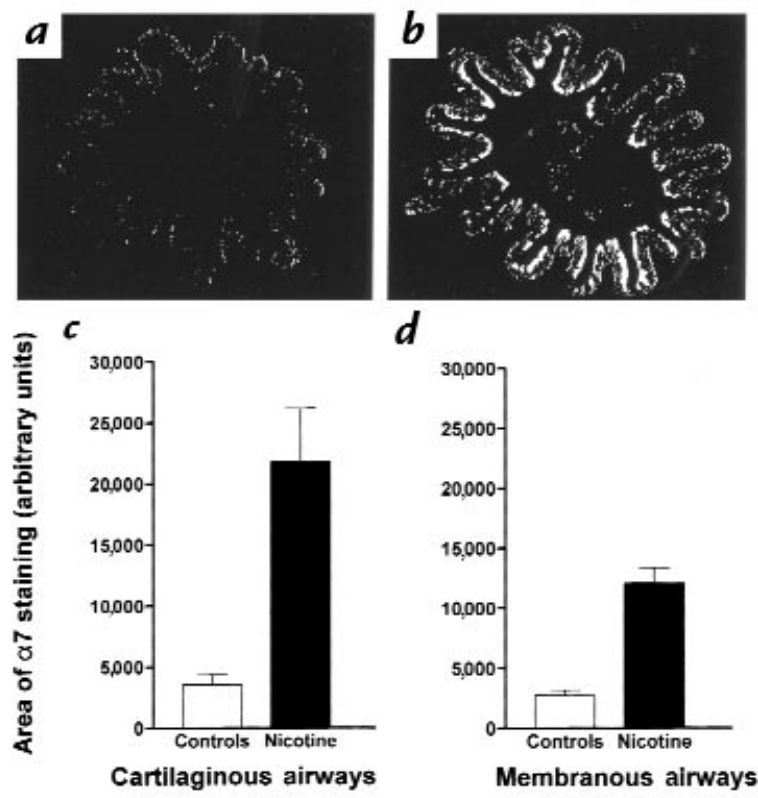

Figure 3

Binary threshold showing representational areas of $\alpha 7$ immunoreactivity in cartilaginous airway epithelial cells from control ( $a)$ and nicotine-exposed (b) fetal lungs. (c) Area of $\alpha 7$ staining in cartilaginous airways from control vs. nicotine-exposed animals $(P=0.015)$. (d) Area of staining in membranous airways from control vs. nicotine-exposed animals $(P=0.003)$.

internal standard to $2 \mathrm{ml}$ of amniotic fluid, and samples were mixed with $2 \mathrm{ml}$ of $5 \mathrm{M} \mathrm{NaOH}$. Then $400 \mu \mathrm{l}$ of methylene chloride was added and mixed on a shaker $(250 \mathrm{rpm})$ for $10 \mathrm{~min}$. The organic layer was separated from the aqueous layer by centrifuging tubes at $2,800 \mathrm{~g}$ for $5 \mathrm{~min}$. The organic layer was pipetted into preweighed conical vials, and the vials were placed in a $80^{\circ} \mathrm{C}$ heating block until $100 \mu \mathrm{l}$ fluid volume remained. The sample was then analyzed by capillary column GC-MS using a DB-5 column; nicotine was eluted at $11.8 \mathrm{~min}$.

Reverse transcriptase-PCR. For reverse transcriptase-PCR (RTPCR), $5 \mu \mathrm{g}$ total RNA prepared from an additional 140 day fetal monkey lung was reverse transcribed in $20 \mu \mathrm{l}$ using an oligo(dT) primer and SuperScript II MMLV reverse transcriptase from GIBCO BRL (Gaithersburg, Maryland, USA). Five microliters of the reverse transcription was then amplified in a $50 \mu \mathrm{l}$ reaction using $50 \mathrm{pmol}$ of the $5^{\prime}$ and $3^{\prime}$ primers in a standard PCR reaction for 35 cycles of $92 \%$ for 30 s, $50 \%$ for $30 \mathrm{~s}$, and $72 \%$ for $1 \mathrm{~min}$. Amplified bands of the right size were gel isolated and subcloned into pGEM-T (Promega Corp., Madison, Wisconsin, USA). Two to four clones with the right sized inserts were miniprepped (Perfect Preps; 5'-3', Boulder, Colorado, USA) and subjected to automated sequencing on an $\mathrm{ABI} 373 \mathrm{XL}$ sequencer. A sequence was obtained on at least two independent subclones to rule out any PCR errors. The $5^{\prime}$ and $3^{\prime}$ primers used to amplify $\alpha 7$ were GGC TTC CGC GGC CTG GAC GGC GTG CAC TGT and CAC AGT GGC CCT GCA GAC CGA TGG TAC GGA, respectively; the $5^{\prime}$ and $3^{\prime}$ primers used to amplify $\alpha 5$ were GAG CAA AGG AAA CAG AAC CGA CAG CTG TTG and AAG TCC ACA GAA ACA TCC GAT CAA GAA CCT, respectively.

In situ bybridization. In situ hybridization was done as described previously (30), with modifications. In brief, $5-\mu \mathrm{m}$ zinc formalin-fixed tissue sections were deparaffinized, rehydrated, and treated with $20 \mu \mathrm{g} / \mathrm{ml}$ proteinase $\mathrm{K}(0.1 \mathrm{M}$ Tris, $0.05 \mathrm{M}$ EDTA; $\mathrm{pH} 8.0$ ) for $20 \mathrm{~min}, 0.1 \mathrm{M}$ triethanolamine, and acetylated with $0.0025 \%$ acetic anhydride. Slides were then rinsed in $2 \times$ SSC, dehydrated in ascending series of ethanol, and vacuum dried. ${ }^{33} \mathrm{P}$-radiolabeled cRNA probes were heated for $5 \mathrm{~min}$, applied to slides, sealed with DPX and incubated at $55^{\circ} \mathrm{C}$ for $16 \mathrm{~h}$. After treatment with ribonuclease-containing buffer $(20 \mu \mathrm{g} / \mathrm{ml}$ RNase A, $0.5 \mathrm{M} \mathrm{NaCl}, 0.01 \mathrm{M}$ Tris, $1 \mathrm{mM}$ EDTA; pH 8.0) at $37^{\circ} \mathrm{C}$ for $30 \mathrm{~min}$ to inactivate nonhybridized probe, the slides were rinsed in a descending series of SSC $(2 \times$ SSC, $1 \times$ SSC, $0.5 \times$ $\mathrm{SSC}$ ) containing $0.1 \mathrm{M} \mathrm{DTT}$ and then incubated (high stringency) in $0.1 \times \mathrm{SSC}$ and $0.1 \mathrm{M} \mathrm{DTT}$ at $65^{\circ} \mathrm{C}$ for $30 \mathrm{~min}$. Sections were dehydrated in an ascending series of alcohol dilutions, vacuum dried, coated with NBT2 autoradiographic emulsion (Kodak, Rochester, New York, USA), stored at $4^{\circ} \mathrm{C}$ for 2 weeks, developed, and counterstained with hematoxylin. For quantification, in situ hybridized sections were exposed to Hyperfilm$\beta \max$ (Amersham Life Sciences Inc., Arlington Heights, Illinois, USA) for 2 days, and the average optical densities of images of sections was determined using the Harmony Image Analysis System (Videk, Rochester, New York, USA; ref. 31).

Homologous probes for rhesus surfactant protein-A (SP-A) and surfactant protein-B (SP-B) were prepared by RT-PCR. To prepare the probes, RNA from the 140-day fetal monkey lung was reverse transcribed then amplified using primers that were highly conserved in humans, rabbits, and rats to generate SP-A and SP-B cDNAs. As described above for nAChR, a 493-bp cDNA was amplified for rhesus SP-A using the $5^{\prime}$ and $3^{\prime}$ primers GGT GTC AAA GGA GAC CCT GC and CGG TAC CAG TTG GTG TAG TT. A 493-bp cDNA was amplified for rhesus SP-B using the $5^{\prime}$ and $3^{\prime}$ primers GCA AAG GAA AAG CCA AGT GAG ACG GGC TCT and AAA AGC TTA ACT TAA CAA TTT CTG ATG TCT. These partial cDNA sequences have been deposited in Genbank with accession nos. AF087691 and AF087692, respectively.

Cytokinetics of type II cells. The number of alveolar cells expressing SP-A mRNA was assessed to determine whether nicotine affected alveolar type II cell cytokinetics. Dark-field images were grabbed with the Sony DKC 5000. Ten fields were randomly selected from sections obtained from three zinc formalin-fixed tissue blocks. SP-A mRNA-positive cells were counted and the number of cells per square millimeter was calculated. Cell counts were limited to alveolar walls. Terminal and respiratory bronchioles were excluded from this analysis to avoid confusion with Clara cells. The labeling index of type II cells was determined by double immunohistochemical staining for proSP-B and the proliferating cell nuclear antigen (PCNA). Labeling index was percentage of proSP-B-positive cells that were also positive for PCNA.

$\alpha B G T$ binding. $\alpha B G T$ binding assay was performed using the method of Breese et al. (32) with some modifications. Lung sections $(5 \mu \mathrm{m})$ from tissue fixed with Bouin's fixative were dewaxed and rehydrated in a descending series of alcohols and TBS (0.05 Tris-buffered saline; $\mathrm{pH}$ 7.4). Adjacent sections were either incubated in binding buffer (TBS $+0.2 \% \mathrm{BSA}$ ) or binding buffer with $2 \mathrm{mM}$ nicotine for nonspecific binding for $1 \mathrm{~h}$

\section{Table 3}

Changes in morphometric parameters of NEB and solitary PNEC in the fetal lungs after chronic maternal nicotine delivery

\begin{tabular}{lccc}
\hline Variable & Control $(n=105)$ & Nicotine $(n=144)$ & $P$ \\
Cells/NEB & $4.7 \pm 0.2$ & $6.4 \pm 0.3$ & $<.001$ \\
NEB area $\left(\mu^{2}\right)$ & $224.2 \pm 9.1$ & $274.0 \pm 12.5$ & 0.003 \\
Cell size in NEB $\left(\mu^{2}\right)$ & $47.7 \pm 1.0$ & $43.2 \pm 0.8$ & $<.001$ \\
NEB/unit lung tissue & $0.36 \pm 0.10$ & $0.51 \pm 0.13$ & 0.42 \\
PNEC/unit lung tissue & $1.10 \pm 0.32$ & $0.86 \pm 0.12$ & 0.52 \\
NEB/PNEC ratio & $0.33 \pm 0.06$ & $0.58 \pm 0.06$ & 0.04
\end{tabular}

Values are mean $\pm \mathrm{SE}$. NEB, neuroepithelial bodies; $P N E C$, pulmonary neuroendocrine cells. 


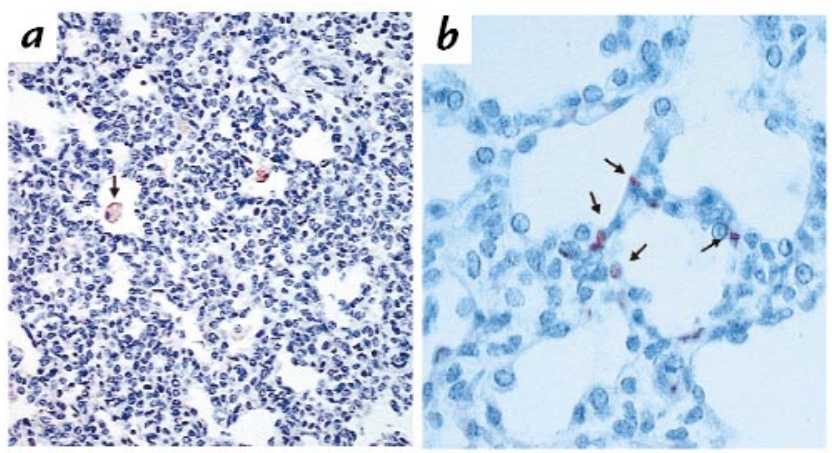

Figure 4

Immunohistochemical localization of nicotinic receptor subtypes in 134-day fetal monkey lung. (a) Anti- $\alpha 1,3,5$ (MAB 210) showing staining in alveolar macrophage. $\times 400$. (b) Anti- $\alpha 1,3,5$ (MAB 210) showing staining in a subset of cells lining developing alveoli. $\times 1,000$. Procedure as described in the research plan: AEC was used as immunoperoxidase substrate, and hematoxylin was used as counterstain. Arrows point to immunostained cells.

at room temperature. Thereafter, sections were incubated with $5 \mathrm{nM}\left[{ }^{125} \mathrm{I}\right] \mathrm{Tyr}^{54} \alpha \mathrm{BGT}$ (specific activity 2,000 Ci/mM; Amersham Life Sciences Inc.) alone or with $2 \mathrm{mM}$ nicotine for $4 \mathrm{~h}$ at $37^{\circ} \mathrm{C}$. Sections were rinsed twice in binding buffer at $37^{\circ} \mathrm{C}$ for $5 \mathrm{~min}$, then three times in TBS for $15 \mathrm{~min}$ and one time in PBS for $5 \mathrm{~min}$. Sections were dehydrated in an ascending series of alcohols and vacuum dried for $2 \mathrm{~h}$. Slides were dipped in NBT2 autoradiographic emulsion (Kodak), stored at $4{ }^{\circ} \mathrm{C}$ for 10 days, developed, and counterstained with hematoxylin.

Colocalization of $\alpha B G T$ and proSP-B. $\alpha$ BGT binding and proSP$\mathrm{B}$ immunolabeling was done to determine if $\alpha 7 \mathrm{nAChRs}$ were present on alveolar type II cells. Cryosections ( $8 \mu \mathrm{m}$ thick) were mounted on Probe-on slides (Fisher Scientific Co., Pittsburgh, Pennsylvania, USA). After bringing the sections to room temperature, they were rehydrated in TBS solution for $20 \mathrm{~min}$. The sections were then treated with nonspecific binding buffer $(\mathrm{TBS}+0.2 \%, \mathrm{BSA}+2 \%$ nonimmune goat serum) for $1 \mathrm{~h}$ at room temperature. Thereafter, sections were incubated with anti-human proSP-B rabbit polyclonal antibody overnight at $4^{\circ} \mathrm{C}$. The sections were rinsed three times in TBS and then incubated in binding buffer alone or containing $5 \mathrm{mM}$ nicotine to determine specificity of $\alpha B G T$ binding for $1 \mathrm{~h}$ at room temperature. Then a cocktail of $15 \mathrm{nM}$ Texas red-conjugated $\alpha \mathrm{BGT}$ (Molecular Probes, Eugene, Oregon, USA) and fluorescein-conjugated anti-rabbit antibody (Vector Laboratories) was applied to the sections and incubated for $3 \mathrm{~h}$ at $37^{\circ} \mathrm{C}$. The sections were rinsed twice in the binding buffer 5 min each, three times in TBS, and then treated with DAPI (Molecular Probes) for $5 \mathrm{~min}$ to counterstain nuclei. Sections were rinsed three times in PBS and mounted with Vectashield (Vector Laboratories Inc.). Colocalization was determined using a confocal microscope.

Amniotic fluid SP-A and SP-B protein measurements. Surfactant protein levels were measured in amniotic fluid samples obtained on days 92, 106, 120, and 134 of gestation by ELISA as described previously $(33,34)$.

Statistical analysis. Means and SEMs were calculated using Number Cruncher Statistical System (NCSS, Kaysville, Utah, USA). Differences between the means of the treatment and control groups were determined by Student's $t$ test.

\section{Results}

On day 26 of pregnancy, rhesus monkeys were subcutaneously implanted with Alzet osmotic minipumps to deliver $1 \mathrm{mg} / \mathrm{kg} /$ day of nicotine. Animals were treated with nicotine from day 26 to 134 of pregnancy, at which time the fetal monkeys were obtained by cesarean section. Nicotine treatment $(n=3)$ did not affect maternal weight gain or noticeably affect food intake (by inspection) as compared with controls $(n=3)$. Nicotine levels in amniotic fluid of treated animals on day 134 of gestation were $15.5 \pm 3.8 \mathrm{ng} / \mathrm{ml}$, consistent with average nicotine levels present in amniotic fluid of pregnant human smokers (35). Nicotine administration reduced fetal body weight by $8 \%$ compared with controls. Similar reductions were also seen in body length, biparietal, and weights of fetal heart, pancreas, adrenals, kidneys, and brain. Lung weight and volume were lower in nicotinetreated fetuses (13\% and $12 \%$, respectively) but not significantly. Because these reductions in weight were relatively small, sample size precluded statistical significance. The decreases seen are consistent, however, in scale with human in utero growth retardation seen with smoking during pregnancy $(1,2)$.
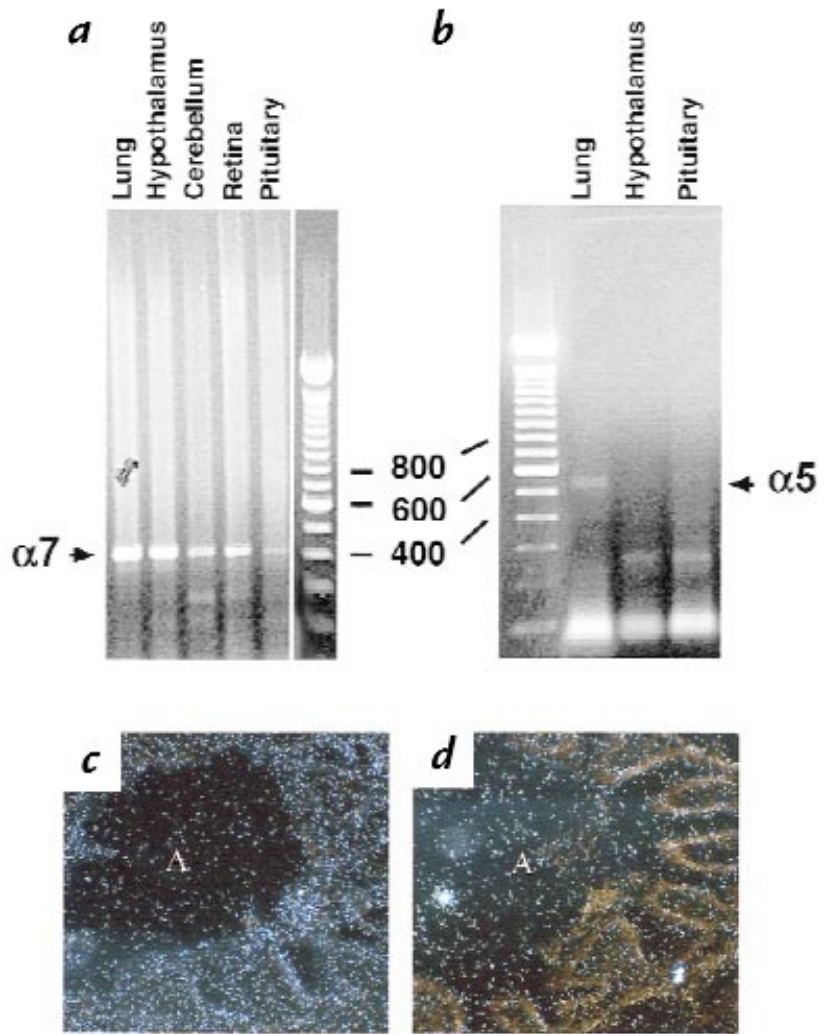

\section{Figure 5}

( $\boldsymbol{a}$ and $\boldsymbol{b}$ ) RT-PCR showing the presence of $\alpha 7(a)$ and $\alpha 5(b)$ nicotinic receptor subunit mRNAs in normal 140-day fetal monkey lung. Primers to the human DNA sequences were used for RT-PCR as described in the methods. Total RNA was prepared from the monkey tissues shown. All tissues except lung were from adult animals. Arrows show the predicted size of bands to be amplified for each subunit. The identity of amplified bands was confirmed by sequence analysis. Lower-molecular-weight bands likely represent nonspecific amplification products. ( $\boldsymbol{c}$ and $\boldsymbol{d}$ ) In situ hybridization analysis showing expression of $\alpha 7 \mathrm{nAChR}$ mRNA surrounding cartilaginous airway in nicotine-exposed 134-day fetal lung. Hybridization was performed with ${ }^{33} \mathrm{P}$-labeled $\mathrm{cRNA}$ probe prepared from amplified monkey $\alpha 7$ mRNA fragment shown in $a . c$ shows antisense; $d$ shows sense. $\times 100$. $n A C h R$, nicotine cholinergic receptor; $R T$, reverse transcriptase. 
Effects of prenatal nicotine on lung structure. Morphometric analysis showed that prenatal exposure to nicotine significantly altered lung structure. Linear intercept, an indicator of airspace size, and volume density of alveolar airspace (Valv) were significantly increased in nicotinetreated fetal lungs (Table 1). At the same time, internal surface area of the lung in nicotine-treated animals was significantly deceased. This is consistent with larger airspaces of less surface complexity resulting from nicotine. Representative illustration of these changes is shown in Fig. 1. No significant changes in volume densities of alveolar duct $(\mathrm{Vd})$, alveolar wall (Vwall), and bronchial lumen (Vbrair) were observed (Table 1).

Nicotinic receptor immunobistochemistry. If nicotine directly affects lung development, nicotinic receptors should be present in fetal lung. Expression of nicotinic receptors in fetal lung was assessed by immunohistochemistry, radioligand binding, and RT-PCR. In 134-day fetal lung, immunohistochemistry using MAB 319, which is specific for $\alpha 7$ (26-28), showed strong immunoreactivity in airway and arterial smooth muscle cells and in fibroblasts surrounding walls of airways and vessels (Fig 2). $\alpha 7$ immunoreactivity was also present in submucous glands, airway-associated nerve fibers, and free pulmonary macrophages. As will be described further, staining was also seen in type II cells and in pulmonary neuroendocrine cells (PNEC). Strikingly, in 134-day fetal lungs from nicotine treated animals, the intensity of $\alpha 7$ immunoreactivity was markedly increased in cartilaginous airway wall cells both in the extra- and sub-cartilaginous regions (Fig. $2 b) . \alpha 7$ immunoreactivity was also markedly increased in blood vessel walls (Fig. 2b). Nicotine treatment also markedly induced $\alpha 7$ expression in airway epithelial cells (Fig. 2d). This increase was seen in cells lining airways from cartilaginous airways (Fig. $2 d$ ) down to respiratory bronchioles (not shown). No background staining was seen when nonimmune serum was substituted for MAB 319 (data not shown). As shown in Fig. 3, the nicotine-induced increase in areas of $\alpha 7$ immunostaining in epithelial cells in cartilaginous airways $(P=0.015)$ and membranous airways $(P=0.003)$ was highly significant.

Immunohistochemistry using antibodies MAB 210 and $\operatorname{MAB} 35(26,36)$, which recognize the $\alpha 1, \alpha 3$, and $\alpha 5$ subunits, showed staining in alveolar macrophages and a subset of cells lining the developing alveolar airspaces (Fig. 4, $a$ and $b$ ). Both antibodies showed similar staining patterns. No major difference in staining intensity with antibodies 210 and 35 was seen with nicotine treatment. Specific antibodies to bacterially expressed human $\alpha 3$ and $\alpha 6$ showed similar patterns as seen with MABs 210 and 35 (data not shown). This indicates that heteromeric, as well as homomeric, forms of the nAChR are expressed in developing alveoli.

Detection of nicotinic receptor $m R N A$. The presence of authentic $\alpha 5$ and $\alpha 7$ subunit RNAs in fetal monkey lung was confirmed by RT-PCR and sequence analysis. Using primers complementary to the human sequences of $\alpha 5$ and $\alpha 7$, RT-PCR was performed, and strong bands were amplified (Fig. 5). The resulting bands were subcloned, sequenced, and found to encode authentic monkey $\alpha 5$ and $\alpha 7$, as indicated by the $>95 \%$ nucleotide homology with the human sequences. These sequences have been deposited in Genbank with accession nos. AF087689 and AF087690, respectively. The expression of $\alpha 7 \mathrm{sub}-$ unit RNA was further confirmed by in situ hybridization (Fig. 5, $c$ and $d$ ) showing the presence of RNA in a pattern similar to that seen in Fig. $2 d$.

In situ $\alpha B G T$ binding. To confirm that the $\alpha 7$ immunoreactivity represented $\alpha 7$ receptors capable of binding ligand, in situ ligand binding with ${ }^{125} \mathrm{I}-\alpha \mathrm{BGT}$ and Texas red $\alpha B G T$ was performed. As shown in Fig. $6 a$, at low power the pattern of ${ }^{125} \mathrm{I}-\alpha \mathrm{BGT}$ binding to 134 -day fetal lung matched perfectly the pattern of immunoreactivity seen in Fig. 2a. At higher power, confocal microscopy with Texas red-labeled $\alpha$ BGT (Fig 6, $b$ and $c$ ), showed that nicotine increased $\alpha B G T$ binding in airway epithelial cells and in airway walls in parallel with the nicotineinduced increases in $\alpha 7$ immunoreactivity evident in Fig. $2, c$ and $d$. The specificity of binding is shown in Fig. $6 d$, in which $5 \mathrm{mM}$ nicotine almost entirely blocks $\alpha \mathrm{BGT}$ binding. Thus, the patterns of $\alpha 7$ immunoreactivity seen in Fig. 2 clearly corresponds to nicotinic receptors capable of binding ligand, and the increased $\alpha 7$ immunoreactivity corresponds to increased ligand binding.

Expression of $\alpha 7$ in developing alveoli and type II cells. ${ }^{125} \mathrm{I}-$ $\alpha B G T$ showed binding over cells in developing alveoli. Morphology of some of these cells was highly suggestive of type II cells (Fig. 7a). This was confirmed by colocalization of Texas red-labeled $\alpha$ BGT binding and proSP-B immunoreactivity (Fig. 7b). Colocalization showed that practically all alveolar type II cells had functional $\alpha 7$ receptors. Interestingly, a subset of cells in developing alveoli that bound $\alpha$ BGT did not express proSP-B (Fig. 7b). Morphologically, these cells were present at the tips of the secondary crest or in the interstitium and appeared to be interstitial fibroblasts. This suggests that a second cell type in airspaces expresses $\alpha 7$ receptors. The precise identity of these cells remains to be determined.

The relative number of type II cells per unit of parenchymal area (developing alveoli and alveolar ducts), as defined by expression of type II cell mRNA, was significantly increased by nicotine exposure (Table 2). This appeared to reflect a stimulation of type II cell mitogenesis, as the percentage of type II cells expressing PCNA was also significantly increased. Consistent with this, at 134 days of gestation, levels of SP-B mRNA in the lung were significantly increased, as were levels of SP-B in amniotic fluid. Levels of SP-A, while increased, were not significantly so.

Effect of nicotine on collagen deposition. Preliminary studies were made to determine if the expression of nicotinic receptors in specific cell types was associated with altered cellular function. The strong expression of $\alpha 7$ receptors in fibroblasts surrounding cartilaginous airways and blood vessels raises the possibility of altered collagen expression. As seen in Fig. 8, nicotine treatment strongly upregulated collagen staining surrounding large airways and vessels. Quantitation of area of collagen-staining surrounding cartilaginous airways $\left(\mu \mathrm{m}^{2}\right.$ of collagen staining per $\mu \mathrm{m}$ of airway epithelial basement membrane) showed an increase from $39.1 \pm 3.1$ in controls to $66.5 \pm 5.9$ in nicotine-exposed animals $P<0.001$ (Fig. 8). This increase in collagen is consistent with the reports of thickened airway walls (37) and altered compliance (6) in infants whose mothers smoked during pregnancy. 

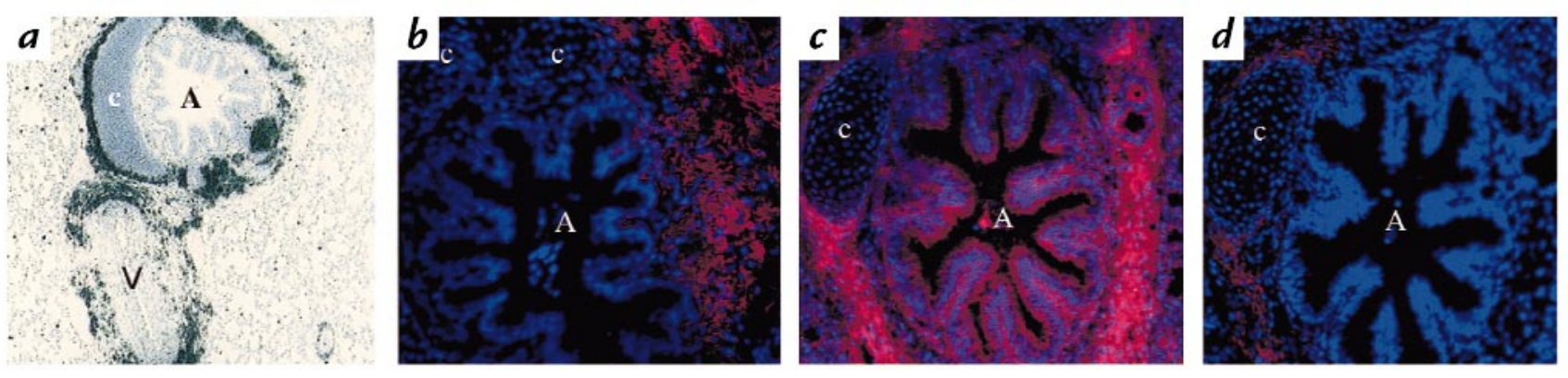

Figure 6

(a) Receptor autoradiography showing binding (black) of ${ }^{125}$ - $\alpha$ BGT to 134 -day fetal monkey lung. $\times 100$. Note the similar pattern of ligand binding as immunostaining in Fig. 2a. (b) Confocal image showing binding of Texas red $\alpha$ BGT (red) to cartilaginous airway from control 134-day fetal monkey lung. $\times 400$. Nuclei are counterstained with DAPI (blue). (c) Similar section as in $a$, but from nicotine-exposed animals, showing strong binding of $\alpha B G T$ to airway epithelial cells and enhanced binding in airway walls. $(d)$ Serial section to $c$ but incubated with Texas red $\alpha B G T$ in the presence of 5 $\mathrm{mM}$ nicotine to show specificity of binding. $A$, airway lumen; $V$, blood vessel lumen; $c$, cartilage; $\alpha B G T, \alpha$-bungarotoxin.

Expression of $\alpha 7$ in pulmonary neuroendocrine cells and neuroepithelial bodies. By dual labeling with antibodies to the $\alpha 7$ receptor and chromogranin $A, \alpha 7$ receptor expression was localized to PNEC and neuroepithelial bodies (NEB) (Fig. 9). These findings indicate that PNEC have $\alpha 7$ receptors and may be the direct target of nicotine to induce the proliferative changes in PNEC and NEB that have been reported in smokers $(38,39)$. Consistent with this, the number of cells per NEB and size of NEB increased significantly in the nicotine-exposed fetal lungs (Table 3). The number of NEB per unit of lung tissue area increased and isolated PNEC per unit of lung tissue area decreased in nicotine-treated fetal lungs. This resulted in a significant increase in the ratio of NEB to isolated PNEC in the nicotine-treated group (Table 3 ). Immunohistochemistry also showed that all PNEC also expressed gastrin-releasing peptide (GRP) (data not shown); thus, nicotine also significantly increased the number of GRP-expressing cells in developing lung.

\section{Discussion}

Epidemiological studies clearly indicate that maternal smoking during pregnancy leads to altered lung function after birth and increased hospitalizations for respiratory illness. The structural changes in lungs caused by maternal smoking and the mechanism underlying these changes are completely unknown. The focus of this study was to determine the extent to which nicotine itself may mediate the effects of smoking on lung development by interaction with nicotinic receptors expressed in the developing lung. To accomplish this, the rhesus monkey provides an ideal model because its degree of lung maturation in utero is similar to that of humans (11, $24,25)$, as opposed to rodents in which a greater part of lung maturation occurs postnatally.

Animals were treated with $1 \mathrm{mg} / \mathrm{kg} /$ day nicotine, a dose equivalent to that of heavy smokers (40) and the dose most commonly used to model human nicotine consumption. This dose resulted in average nicotine levels in amniotic fluid of $15.4 \pm 3.9 \mathrm{ng} / \mathrm{ml}$, equivalent to the levels of nicotine found in amniotic fluid of pregnant smokers (35). This demonstrates that the dose used was appropriate to model smoking during pregnancy. By comparison, light smokers would typically receive one-half this dose, and transdermal nicotine and nicotine gum would deliver one-fourth and one-eighth this dose, respectively (41).

Monkeys were exposed to nicotine from days 26 to 134 of gestation, at which time they were delivered by cesarean section. Lungs from 134-day fetal monkeys are equivalent to lungs from a 32-week-old human fetus and are in the late saccular/early alveolar phase $(24,25)$. This time point was chosen because it allows detection of changes in both lung maturation and development. In the present study, nicotine treatment increased the size (mean linear intercept) and volume density of primitive alveoli and decreased surface area. These observations, in conjunction with decreased lung volume, suggest that nicotine exposure may result in larger but fewer potential airspaces, thus downregulating the surface complexity of lung. These findings are similar to findings from two other models of effects of smoking on lung development. Collins et al. (8) exposed pregnant rats to cigarette smoke and similarly found enlarged and fewer saccules in fetal rats after cigarette smoke exposure. Maritz et al. $(9,42)$ treated rats with a combination of pre- and postnatal nicotine and similarly found decreased radial alveolar count and increased mean linear intercept in neonatal rats. The finding that nicotine alters alveolar development in both monkeys and rodents makes it highly likely that prenatal exposure to nicotine will similarly affect human lung development.

For nicotine to directly affect lung development, nicotinic cholinergic receptors must be present in fetal lungs. Because all nicotinic receptors contain $\alpha$ subunits, immunohistochemistry using antibodies against the $\alpha$ subunits presents a good approach to initial screening for the presence of nicotinic receptors. Immunohistochemistry using antibodies specific for $\alpha 7$ recognized cells in developing alveoli, airway epithelial cells, submucous glands, airway-associated nerve fibers, airway and arterial smooth muscle cells, fibroblasts in walls of airways and vessels, and free alveolar macrophages. The immunohistochemical staining intensity was dramatically increased after nicotine exposure, particularly in the airway epithelial cells and in airway and vessel walls (Figs. 2 and 3). Staining was more intense in the paracartilaginous regions of airway walls where fibroblasts are most abundant (Fig. 2d). Prenatal nicotine exposure markedly 

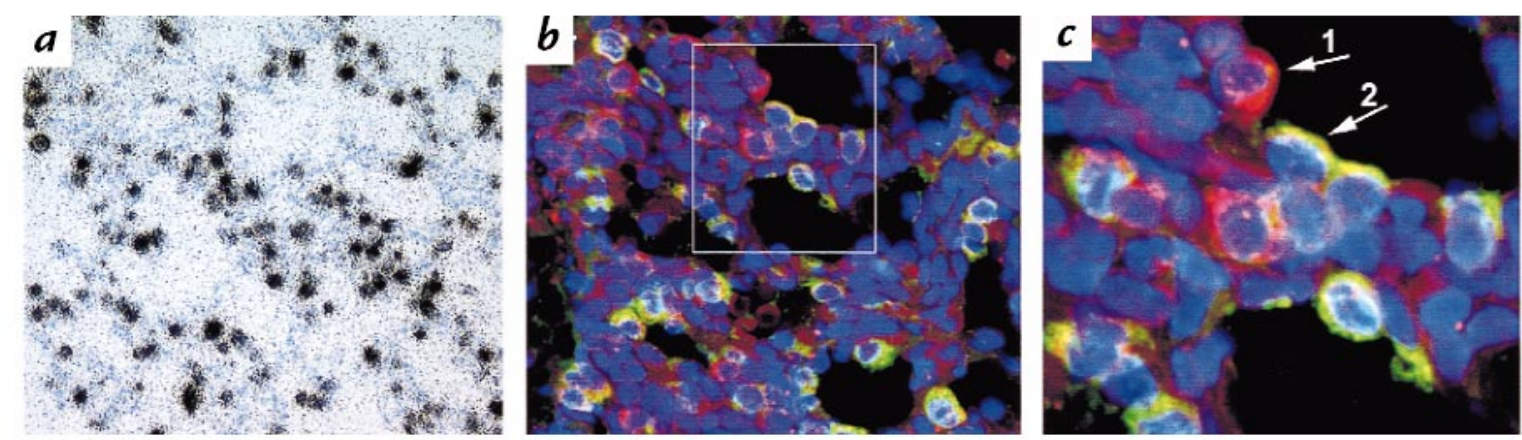

\section{Figure 7}

(a) Receptor autoradiography showing binding of ${ }^{125}$ I- $\alpha$ BGT to cells morphologically consistent with type II cells. (b) Dual-labeling confocal microscopy showing colocalization of $\alpha B G T$ with proSP-B. Red represents Texas red $\alpha B G T$; green represents proSP-B; yellow represents overlap of red and green; and blue represents DAPI nuclear stain. (c) Higher-power view of boxed region in $b$ showing two populations of $\alpha B G T$-positive cells. Dual labeling showing subset of alveolar cells that express $\alpha$ BGT but no proSP-B (arrow 1), and those that express $\alpha$ BGT and proSP-B (arrow 2 ).

increased receptor expression in airway epithelial cells in cartilaginous and membranous airways (Figs. 2 and 3 ). Thus, nicotine upregulates the $\alpha 7$ nAChR expression. The presence of authentic $\alpha 7$ receptors in the developing lung was also confirmed by RT-PCR, sequence analysis, and by in situ hybridization (Fig. 5). Further validating the identity of the intense $\alpha 7$ immunostaining in the connective tissue surrounding the large airways are our preliminary observations that wild-type mice show similar $\alpha 7$ immunostaining, but $\alpha 7$ receptor knockout mice (43) show no such staining (Sekhon, H.S., unpublished data).

The upregulation of $\alpha 7$ immunoreactivity is dramatic. This strongly suggests that nicotine crosses the placenta and interacts with nicotinic receptors in the developing lung. Peng et al. (13) and Olale et al. (44) have shown that chronic nicotine exposure both upregulates $\alpha 7$ receptors and permanently inhibits the function of many of these nAChR. Olale et al. (44) have shown that $\alpha 7$ receptors are exquisitely sensitive to inactivation by nicotine with an $\mathrm{IC}_{50}$ of $0.0028 \mu \mathrm{M}$. Thus, prenatal nicotine exposure most likely leads to increased levels of inactivated $\alpha 7$ receptors in the developing lung. This would alter normal cholinergic transmission both by blocking the normal functioning of $\alpha 7$ receptors and by allowing unopposed signaling by other nicotinic receptor subtypes (e.g., $\left.\alpha_{3} \alpha_{5}, \beta_{2 \text { or } 4}\right)$ that are more resistant to inactivation by chronic nicotine (44). Alternately, nanomolar concentrations of nicotine acting through the $\alpha 7$ receptor have been shown to facilitate neurotransmission in the central nervous system $(45,46)$. Thus, a stimulatory role for nicotine on $\alpha 7$ receptors cannot be ruled out. Clarification of the exact mechanism will require measurement of calcium changes in response to nicotine and acetylcholine. Regardless of how signal transduction is changed, clearly chronic prenatal nicotine affects nicotinic receptor expression.

The ability of $\alpha 7$ receptors to bind ligand was demonstrated both with ${ }^{125} \mathrm{I}-\alpha \mathrm{BGT}$ binding and with Texas red $\alpha B G T$ binding. The pattern of ligand binding obtained by both methods exactly matched the expression pattern seen by immunohistochemistry. As seen in Fig. 6, $b$ and $c$, Texas red-labeled $\alpha$ BGT binding increased with nicotine treatment. While the increase in fluorescent binding was not quantified, binding to airway epithelial was obviously increased consistent with the increase in $\alpha 7$ immunoreactivity. This result agrees with the multiple reports that chronic exposure to nicotine both in vivo and in vitro increases nicotinic ligand binding $(13,14,44)$. This is also consistent with reports that prenatal exposure to nicotine increases nicotinic receptor expression in mouse brains (17) and that nicotinic receptor expression is increased in brains of adult smokers (14). The specificity of the $\alpha B G T$ binding is clearly shown in Fig. $7 d$, where coincubation with $5 \mathrm{mM}$ of nicotine blocked almost all $\alpha$ BGT binding.

The strong upregulation of $\alpha 7$ subunit expression in fibroblasts suggests possible effects of nicotine on connective tissue synthesis. This is clearly the case, as shown by the increase in collagen staining around large
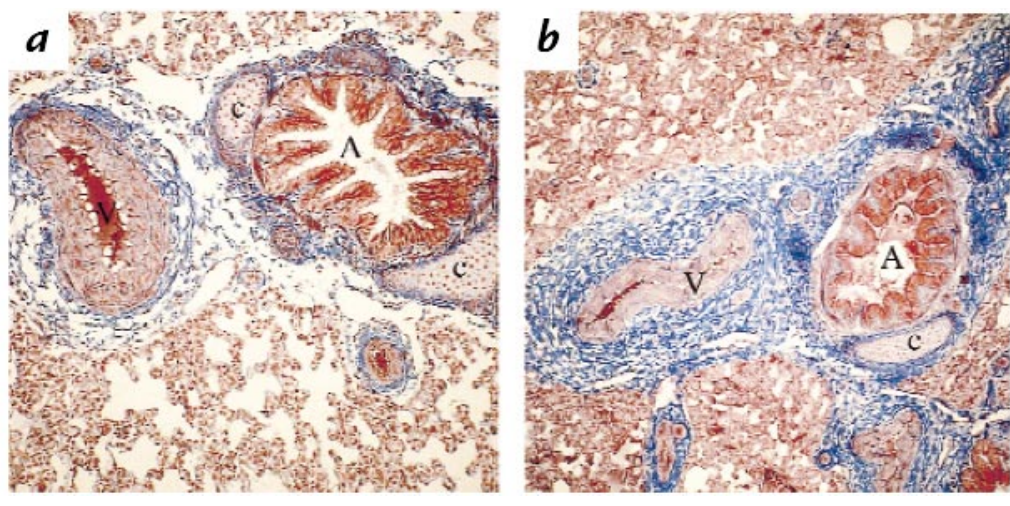

Figure 8

Masson's trichrome stain showing increased collagen deposition in 134-day fetal lung from control (a) vs. nicotine-exposed $(\boldsymbol{b})$ animals. $A$, airway lumen; $V$, blood vessel lumen; $c$, cartilage. $\times 100$. Quantitation of collagen staining as described in Methods showed average area of collagen staining in controls (normalized for airway size $)=39.1 \pm 3.1$, and in nicotine-exposed $=66.5 \pm 5.9 ; P<0.001$. 

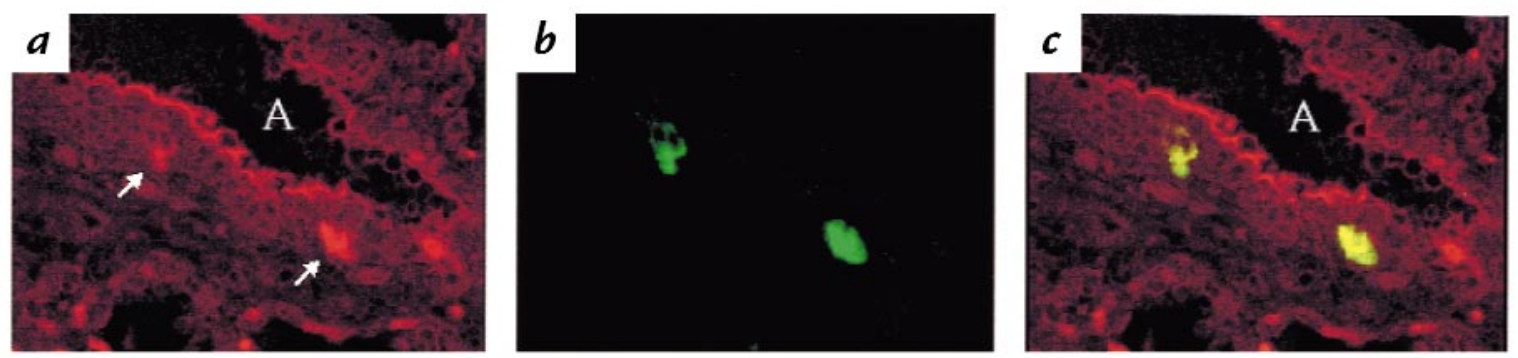

Figure 9

Confocal image of dual immunofluorescent staining showing colocalization of $\alpha 7 \mathrm{nAChR}$ and chromogranin $\mathrm{A}$ in PNEC in respiratory bronchioles of nicotine-exposed fetal monkey lung. (a) $\alpha 7$ immunoreactivity. (b) Chromogranin A. (c) Overlap in yellow. A, airway (bronchiole) lumen. $\times 250$. Arrows in a point to cells that are clearly positive for both chromogranin $A$ and $\alpha 7$. PNEC, pulmonary neuroendocrine cells.

airways (Fig. 8). Connective tissue proteins are primarily synthesized by fibroblasts (11), and cigarette smoke stimulates proliferation of wall cells of all bronchial, bronchiolar, and alveolar duct-associated vessels (47). Nicotine may therefore directly stimulate $\alpha 7$ nAChRbearing fibroblasts to lay down an excessive amount of connective tissue. This finding is consistent with the recent report by Elliot et al. (37) of increased airway wall thickness in infants who died of sudden infant death syndrome (SIDS) and whose mothers smoked during pregnancy. Our findings suggest that increased collagen deposition stimulated by the interaction of nicotine with fibroblasts leads to the increased airway wall thickness that Elliot et al. (37) observed. Studies to determine the mechanism by which nicotine stimulates collagen expression in these cells is currently underway. Our finding that nicotine increases collagen deposition around airways would also be consistent with the decreased respiratory velocities observed in infants whose mothers smoke during pregnancy (4-6). Increased collagen deposition around pulmonary vessels may also underlie the increased incidence of persistent pulmonary hypertension found in infants of smoking mothers (48).

Expression of $\mathrm{nAChR}$ in developing lung is not limited to $\alpha 7$ subtypes. MABs recognizing $\alpha 1, \alpha 3$, and $\alpha 5$ subunits were positive for cells in the developing alveoli and in pulmonary macrophage. This same population of cells was also positive with antisera specific for $\alpha 3$ and $\alpha 6$ subunits. Because the presence of $\alpha 5$ in lung was also confirmed by RT-PCR, it appears that cells in the alveoli and pulmonary macrophages also express $\alpha 3$, $\alpha 5$, and $\alpha 6$ receptors. This suggests the presence in these cell types of heteromeric forms of the nicotinic receptor composed of $\alpha 3, \alpha 5, \alpha 6$, and $\beta 2$ and/or $\beta 4$ subunits. These heteromeric forms of the nicotinic receptor have previously been described in peripheral ganglionic neurons (49) and have been shown to form functional receptors in Xenopus oocytes (36) or permanently transfected cells (50). Recently, Maus et al. (19) reported the presence of active $\mathrm{nAChR}$ containing $\alpha 3$ and $\alpha 5$ subunits in bronchial epithelial cells. Thus, our finding of these subunits in alveolar epithelia is consistent with those findings. This suggests that cells in the developing alveoli likely express both homomeric $(\alpha 7)_{5}$ $\mathrm{nAChR}$ and heteromeric $\alpha_{3} \alpha_{5} \beta_{2 \text { or } 4} \mathrm{nAChR}$, as has been described in neurons (49).
Coexpression studies localized $\alpha 7$ receptors to type II cells as defined by expression of proSP-B. Nicotine treatment significantly increased both the number of type II cells and the labeling index of type II cells. This suggests a direct mitogenic effect of nicotine on type II cells, though increased formation of type II cells from precursors cannot be ruled out. Consistent with this, at 134 days of gestation, levels of SP-B mRNA in lung and SP-B apoprotein in amniotic fluid were significantly increased; levels of SP-A mRNA and SP-A were also increased, but not significantly. These findings are consistent with Wuenschell et al. (51), who found increased levels of SP-A and SP-C mRNA expression in mouse lung treated with nicotine in vitro. This is also consistent with the increased levels of surfactant in amniotic fluid of pregnant smokers $(34,52)$.

Colocalization studies identified $\alpha 7$ receptors in PNEC. PNEC were identified by expression of chromogranin A, though the PNEC also expressed GRP (data not shown). Nicotine exposure increased the size and number of NEB and conversely decreased solitary PNEC. This suggests that nicotine treatment may stimulate mitogenesis in already differentiated PNEC leading to formation of NEB rather than differentiation of new PNEC. Our observation that nicotine stimulates NEB growth is consistent with studies by Chen et al. (38) and Keith and Cary (39), who found increased size of NEB in both humans and rodents exposed to smoke in utero. Similarly, Cutz et al. (53) has found increased GRP in NEB of infants exposed to maternal smoking. Thus, it is clear that the effect of smoking on PNEC proliferation is mediated by nicotine. This is further supported by the studies of Nylen et al. (54), who demonstrated that nicotine stimulates replication of hamster PNEC in vitro. Suggesting that the proliferative effect of nicotine is mediated by $\alpha 7$ receptors, Quik et al. (20) have shown $\alpha$ BGT blocks the nicotine-induced proliferation of a PNEC-related cell line. Taken together, this data suggests that nicotine acting through $\alpha 7$ receptors induces proliferation of PNEC in the developing lung. Neuroendocrine cells express a variety of mitogenic factors that can modulate cellular maturation process in the lungs. Thus, it is likely that some of the effects of nicotine on lung development are mediated by growth factors released from PNEC. Further studies are clearly needed to characterize how the nicotine-induced stimulation of PNEC changes normal lung development. 
The presence of nAChRs on free alveolar macrophages is an intriguing finding. Not only in fetal lungs, but also in adults, activation of macrophages can start a cascade of events resulting in structural changes in the lung. It is likely that under the influence of nicotine in cigarette smoke, nAChRs on macrophages will stimulate expression of various cytokines.

Several key questions remain unanswered. First, what are the mechanistic steps that lead from nicotine's interaction with $\mathrm{nAChR}$ to altered lung development. Second, what are the critical periods and corresponding sites of nicotinic receptor expression in the fetal lung. Third, how does maternal smoking lead to altered pulmonary function and increased evidence of respiratory illness $(3,4)$ in human infants. One hypothesis is that the nicotine-induced lung hypoplasia we describe here could decrease reserve pulmonary capacity and explain the increased respiratory illness. The alterations in collagen deposition we describe could help explain the decreased compliance and expiratory flow rates (4-6). It is important, however, to keep in mind that important roles may also be played by smoking-induced changes in airway branching, elastic tissue synthesis, innervation, or smooth muscle deposition.

It is important to point out two limitations of this study. First, sample size was limited. Thus, while conclusions as to the robust effects of nicotine on $\alpha 7$ receptor expression, collagen expression, and alveolar structure could be determined, smaller effects such as stimulation of surfactant-A expression were not statistically significant. Second, control animals were not implanted with minipumps allowing for potential effects of differences in anesthetic and antibiotic exposure between the two groups. However, differences were minimized because both groups received anesthesia and antibiotics for ultrasound and amniocenteses. In addition, we have previously shown that in pregnant rats, surgical stress and anesthesia does not effect lung weight or lung bombesin-like immunoreactivity (55). Finally, it is important to point out that although we have concentrated on the $\alpha 7$ receptor because its expression is so dramatically changed by nicotine, the other nAChR subtypes also are likely to play important roles in mediating the effects of nicotine on lung development.

In summary, nicotine produced lung hypoplasia with structural alterations and reduced complexity of the gasexchange surface. Nicotine clearly has multiple targets in the developing lung with different critical periods of maximal sensitivity for each target. Nicotine acts at the level of large airways, PNEC, alveoli, and type II cells in different ways at each target. Thus, the overall effect of nicotine on lung development represents the sum of the multiple sites and times of action. Further studies to identify the critical periods and targets of nicotine on lung development are clearly needed. However, given the similarity of rhesus monkey lung development to human lung development and that the dose of nicotine studied is similar to that of human smokers, it is likely that similar effects of nicotine as reported here also occur in human infants whose mothers smoke during pregnancy. These findings also suggest that the much of the effect of smoking on lung development is mediated by nicotine.

\section{Acknowledgments}

The authors wish to thank Anda Cornea for assistance with confocal imaging; John Fanton, Darla Jacob, and Roger Simons of the Oregon Regional Primate Research Center Division of Animal Resources for assistance with timed-pregnant monkeys; and Brian T. Mader and Lorne M. Isabelle for assistance with nicotine assays. This research was supported by National Institutes of Health grants RR-00163 (to E.R. Spindel), HD/HL37131 (to E.R. Spindel), HL-56387 (to J.A. Whitsett), HL-38859 (to J.A. Whitsett), and NS-11323 (to J. Lindstrom).

1. Cliver, S.P., et al. 1995. The effect of cigarette smoking on neonatal anthropometric measurements. Obstet. Gynecol. 85:625-630.

2. Kramer, M.S. 1987. Intrauterine growth and gestational duration determinants. Pediatrics. 80:502-511.

3. Taylor, B., and Wadsworth, J. 1987. Maternal smoking during pregnancy and lower respiratory tract illness in early life. Arch. Dis. Child. 62:786-791.

4. Tager, I.B., et al. 1992. Lung function, pre- and post-natal smoke exposure, and wheezing in the first year of life. Am. Rev. Respir. Dis. 147:811-817.

5. Hanrahan, J., et al. 1992. The effect of maternal smoking during pregnancy on early infant lung function. Am. Rev. Respir. Dis. 145:1129-1135.

6. Cunningham, J., Dockery, D.W., and Speizer, F.E. 1994. Maternal smoking during pregnancy as a predictor of lung function in children. Am.J. Epidemiol. 139:1139-1152.

7. Stoddard, J.J., and Gray, B. 1997. Maternal smoking and medical expenditures for childhood respiratory illness. Am. J. Public Health. 87:205-208.

8. Collins, M.H., et al. 1985. Fetal lung hypoplasia associated with maternal smoking: a morphometric analysis. Pediatr. Res. 19:408-412.

9. Maritz, G.S., Woolward, K.M., and du Toit, G. 1993. Maternal nicotine exposure during pregnancy and development of emphysema-like damage in the offspring. S. Afr. Med. J. 83:195-198.

10. Maritz, G.S., and Thomas, R.A. 1995. Maternal nicotine exposure: response of type II pneumocytes of neonatal rat pups. Cell Biol. Int. 19:323-331.

11. Thurlbeck, W.M. 1995. Lung growth and development. In Pathology of the lung. W.M. Thurlbeck and A.M. Churg, editors. Thieme Medical Publishers. New York, NY. 37-88.

12. Lindstrom, J., et al. 1996. Structure and function of neuronal nicotinic acetylcholine receptors. Prog. Brain Res. 109:125-37.

13. Peng, X., Gerzanich, V., Anand, R., Wang, F., and Lindstrom, J. 1997. Chronic nicotine treatment up-regulates $\alpha 3$ and $\alpha 7$ acetylcholine receptor subtypes expressed by the human neuroblastoma cell line SH-SY5Y. Mol. Pharmacol. 51:776-784.

14. Breese, C.R., et al. 1997. Effect of smoking history on $\left[{ }^{3} \mathrm{H}\right]$ nicotine binding in human postmortem brain. J. Pharmacol. Exp. Ther. 282:7-13.

15. Marks, M.J., et al. 1992. Nicotine binding and nicotinic receptor subunit RNA after chronic nicotine treatment. J. Neurosci. 12:2765-2784

16. van de Kamp, J.L., and Collins, A.C. 1994. Prenatal nicotine alters nicotinic receptor development in the mouse brain. Pharmacol. Biochem. Behav. 47:889-900.

17. Slotkin, T.A., Orband-Miller, L., and Queen, K.L. 1987. Development of $\left[{ }^{3} \mathrm{H}\right]$ nicotine binding sites in brain regions of rats exposed to nicotine prenatally via maternal injections or infusions. J. Pharmacol. Exp. Ther. 242:232-237.

18.Zia, S., Ndoye, A., Nguyen, V.T., and Grando, S.A. 1997. Nicotine enhances expression of the alpha 3 , alpha 4, alpha 5, and alpha 7 nicotinic receptors modulating calcium metabolism and regulating adhesion and motility of respiratory epithelial cells. Res. Commun. Mol. Pathol. Pharmacol. 97:243-262.

19. Maus, A.D.J., et al. 1998. Human and rodent bronchial epithelial cells express functional nicotinic acetylcholine receptors. Mol. Pharmacol. 54:779-788.

20. Quik, M., Chan, J., and Patrick, J. 1994. alpha-Bungarotoxin blocks the nicotinic receptor mediated increase in cell number in a neuroendocrine cell line. Brain Res. 655:161-167.

21. Pau, K.Y., Berria, M., Hess, D.L., and Spies, H.G. 1993. Preovulatory gonadotropin-releasing hormone surge in ovarian-intact rhesus macaques. Endocrinology. 133:1650-1656.

22. Scherle, W. 1970. Simple method for volumetry of organs in quantitative stereology. Mikroskopie. 26:57-60.

23. Weibel, E.R. 1979. Stereological methods. Practical methods for biological morphometry, Volume 1. Academic Press. London, United Kingdom. 1-179.

24. Ten Have-Opbroek, A.A.W. 1981. The development of the lung in mammals: an analysis of concepts and findings. Am. J. Anat. 162:201-219.

25. Ten Have-Opbroek, A.A., and Plopper, C.G. 1992. Morphogenetic and functional activity of type II cells in early fetal rhesus monkey lungs. A comparison between primates and rodents. Anat. Rec. 234:93-104.

26. Lindstrom, J. 1996. Neuronal nicotinic acetylcholine receptors. In Ion channels. T. Narahashi, editor. Plenum Press. New York, NY. 377-450.

27. Schoepfer, R., Conroy, W.G., Whiting, P., Gore, M., and Lindstrom, J. 1990. Brain alpha-bungarotoxin binding protein cDNAs and MAbs 
reveal subtypes of this branch of the ligand-gated ion channel gene superfamily. Neuron. 5:35-48.

28. Peng, X., Katz, M., Gerzanich, V., Anand, R., and Lindstrom, J. 1994. Human alpha 7 acetylcholine receptor: cloning of the alpha 7 subunit from the SH-SY5Y cell line and determination of pharmacological properties of native receptors and functional alpha 7 homomers expressed in Xenopus oocytes. Mol. Pharmacol. 45:546-554.

29. Pankow, J.F., et al. 1997. Conversion of nicotine in tobacco smoke to its volatile and available free-base form through the action of gaseous ammonia. Environ. Sci. Technol. 31:2428-2433.

30. Li, K., Nagalla, S.R., and Spindel, E.R. 1994. A rhesus monkey model to characterize the role of gastrin-releasing peptide (GRP) in lung development. Evidence for stimulation of airway growth. J. Clin. Invest. 94:1605-1615.

31. Li, C., Chen, P., and Smith, M.S. 1998. The acute suckling stimulus induces expression of neuropeptide Y (NPY) in cells in the dorsomedial hypothalamus and increases NPY expression in the arcuate nucleus. Endocrinology. 139:1645-1652.

32. Breese, C.R., et al. 1997. Comparison of the regional expression of nicotinic acetylcholine receptor alpha7 $\mathrm{mRNA}$ and [125I]-alpha-bungarotoxin binding in human postmortem brain. J. Comp. Neurol. 387:385-398.

33. Plopper, C.G., et al. 1992. Acceleration of alveolar type II cell differentiation in fetal rhesus monkey lung by administration of EGF. Am. J. Physiol. 262:L313-L321.

34. Pryhuber, G.S., Hull, W.M., Fink, I., McMahan, M.J., and Whitsett, J.A. 1991. Ontogeny of surfactant proteins A and B in human amniotic fluid as indices of fetal lung maturity. Pediatr. Res. 30:597-605.

35. Luck, W., Nau, H., Hansen, R., and Steldinger, R. 1985. Extent of nicotine and cotinine transfer to the human fetus, placenta and amniotic fluid of smoking mothers. Dev. Pharmacol. Ther. 8:384-395.

36. Wang, F., et al. 1996. Assembly of human neuronal nicotinic receptor alpha5 subunits with alpha3, beta2, and beta4 subunits. J. Biol. Chem. 271:17656-17665.

37. Elliot, J., Vullermin, P., and Robinson, P. 1998. Maternal cigarette smoking is associated with increased inner airway wall thickness in children who die from sudden infant death syndrome. Am. J. Respir. Crit. Care Med. 158:802-806

38. Chen, M.F., Kimizuka, G., and Wang, N.S. 1987. Human fetal lung changes associated with maternal smoking during pregnancy. Pediatr. Pulmonol. 3:51-58.

39. Keith, I.M., and Cary, J.R. 1988. Maternal smoking during pregnancy affects neuroendocrine cells in the neonate hamster lung. Histol. Histopathol. 3:215-222.

40. Benowitz, N.L., and Jacob, P., III. 1984. Daily intake of nicotine during cigarette smoking. Clin. Pharmacol. Ther. 35:499-504.
41. Benowitz, N.L., Chan, K., Denaro, C.P., and Jacob, P. 1991. Stable isotope method for studying transdermal drug absorption: the nicotine patch. Clin. Pharmacol. Ther. 50:286-293.

42. Maritz, G.S., and Thomas, R.A. 1994. The influence of maternal nicotine exposure on the interalveolar septal status of neonatal rat lung. Cell Biol. Int. 18:747-757.

43. Orr-Urtreger, A., et al. 1997. Mice deficient in the alpha7 neuronal nicotinic acetylcholine receptor lack alpha-bungarotoxin binding sites and hippocampal fast nicotinic currents. J. Neurosci. 17:9165-9171.

44. Olale, F., Gerzanich, V., Kuryatov, A., Wang, F., and Lindstrom, J. 1997. Chronic nicotine exposure differentially affects the function of human $\alpha 3, \alpha 4$, and $\alpha 7$ neuronal nicotinic receptor subtypes. J. Pharmacol. Exp. Ther. 283:675-683.

45. Gray, R., Rajan, A.S., Radcliffe, K.A., Yakehiro, M., and Dani, J.A. 1996. Hippocampal synaptic transmission enhanced by low concentrations of nicotine. Nature. 383:713-716.

46. McGehee, D.S., Heath, M.J., Gelber, S., Devay, P., and Role, L.W. 1995. Nicotine enhancement of fast excitatory synaptic transmission in CNS by presynaptic receptors. Science. 269:1692-1696.

47. Sekhon, H.S., Wright, J.L., and Churg, A. 1994. Cigarette smoke causes rapid cell proliferation in small airways and associated pulmonary arteries. Am. J. Physiol. 267:L557-L563.

48. Bearer, C., Emerson, R.K., O'Riordan, M.A., Roitman, E., and Shackleton, C. 1997. Maternal tobacco smoke exposure and persistent pulmonary hypertension of the newborn. Environ. Health Perspect. 105:202-206.

49. Conroy, W.G., and Berg, D.K. 1995. Neurons can maintain multiple classes of nicotinic acetylcholine receptors distinguished by different subunit compositions. J. Biol. Chem. 270:4424-4431.

50. Wang, F., et al. 1998. Chronic nicotine treatment upregulates human $\alpha 3 \alpha 2$, but not $\alpha 3 \alpha 4$ AChRs stably transfected in human embryonic kidney cells. J. Biol. Chem. 273:28721-28732.

51. Wuenschell, C.W., Zhao, J.S., Tefft, J.D., and Warburton, D. 1998. Nicotine stimulates branching and expression of SP-A and SP-C mRNAs in embryonic mouse lung culture. Am. J. Physiol. 274:L165-L170.

52. Lieberman, E., et al. 1992. Association of intrauterine cigarette smoke exposure with indices of fetal lung maturation. Obstet. Gynecol. 79:564-570.

53. Cutz, E., Perrin, D.G., Hackman, R., and Czegledy-Nagy, E.N. 1996. Maternal smoking and pulmonary neuroendocrine cells in sudden infant death syndrome. Pediatrics. 98:668-672.

54. Nylen, E.S., et al. 1993. Cholinergic-nicotinic control of growth and secretion of cultured pulmonary neuroendocrine cells. Anat. Rec. 236:129-135.

55. Khadempour, M.H., Ofulue, A.F., Sekhon, H.S., Cherukupalli, K.M., and Thurlbeck, W.M. 1992. Changes of growth hormone, somatomedin C, and bombesin following pneumonectomy. Exp. Lung Res. 18:421-432. 